\title{
Analysis of the influence of plyometric training in improving the performance of athletes in rhythmic gymnastics
}

\author{
Barbara Raquel Agostini ${ }^{1}$, Edson Marcos de Godoy Palomares ${ }^{1}$, Rosane de Almeida \\ Andrade $^{2}$, Francisco Nataniel Macêdo Uchôaz ${ }^{2,3}$, Nilton Alves ${ }^{4,5^{*}}$
}

\begin{abstract}
Rhythmic gymnastics (RG) athletes need high-performance training since a high degree of precision is required in their exercises. Plyometric training (PT) has been used to improve athletes' neuromuscular function, explosive performance and strength in competition. The object of this study was to assess the efficiency of PT in improving the performance of RG athletes in the juvenile and adult categories over 12 months, by incorporating PT into two training macrocycles. Thirty athletes were selected; they were divided randomly into a control group (CG) and an experimental group (EG) of 15 athletes each. Two 6-month training macrocycles were drawn up for the EG in which they maintained normal training with the addition of PT. The CG maintained its normal training. Three tests were used for the assessment: vertical jump, horizontal jump and agility, assessed at 5 different moments. After 12 months it was observed an improvement in test performance in both groups, with a more significant improvement in the EG when compared to the CG. The addition of PT to normal training improved the performance of athletes by developing greater power in the lower limbs, increasing their capacity in vertical jump, horizontal jump and agility.

Keywords: plyometric training, rhythmic gymnastics, athletes.
\end{abstract}

\section{INTRODUCTION}

Rhythmic gymnastics (RG), with its style of body control and its physical demands, requires great qualities (Mirela, Raducu, Antoanela, Carmen \& Laura, 2014). These gymnasts must have physical strength, flexibility, agility, coordination, balance and grace, as well as optimum functioning of the neuromuscular system (Gaiole \& Patil, 2016). RG gymnasts start to practice the sport from a very young age, requiring intense physical training with many hours spent in the gymnasium, resulting in a high number of injuries (Maffuli, 1990). The injury rate among gymnasts is exceeded only by soccer, wrestling and softball (Chimera, Swanik, Swanik \& Straub, 2004). Particularly, female athletes who perform jumping movements present a higher risk of non-contact anterior cruciate ligament injuries than their male counterparts (Chimera et al., 2004; Wright \& De Cree, 1998).

RG requires strength training to improve jumping ability, however, a low degree of muscular hypertrophy is a pre-requisite for slenderness and "lightness" (Di Cagno et al., 2010). Regular training reduces the likelihood of sport-related injuries, improves motor skills and facilitates weight control (Piazza et al., 2014). RG gymnasts must carry out a variety of movements, including vertical jumps and frequent changes of movement, posture and tension. Many of these attributes are developed simply by practicing normal gymnastic routines, however supplementing this with Plyometric training (PT) appears to facilitate gymnasts' progress in developing strength and speed (Hewett, Stroupe, Nance \& Noyes, 1996). PT is a specialised, high intensity training method, with the object of

\footnotetext{
Manuscript received at September 26 ${ }^{\text {th }} 2016$; Accepted at April 11 2017

${ }^{1}$ Universidade de Cultura Física, Esporte, Juventude e Turismo da Rússia, Moscow, Rússia.

${ }^{2}$ Universidade de Trás-os-Montes- Alto Douro, Vila Real, Portugal.

${ }^{3}$ Faculdade Integrada Da Grande Fortaleza-FGF, Fortaleza, Brasil.

${ }^{4}$ Facultad de Odontología, Universidad de La Frontera, Temuco, Chile.

${ }^{5}$ Centro de Investigación en Morfología Aplicada Reconstructiva y Forense, Temuco, Chile.

* Corresponding author: Facultad de Odontología, Universidad de La Frontera, Avenida Francisco Salazar, 1145,

Casilla 54-D, Temuco, Chile.E-mail: niltonnalves@ufrontera.cl
} 
increasing specific explosive strength for RG and improving the rate of strength development (Adams, O'Shea, O'Shea, \& Climstein, 1992). In addition to enhancing athletic performance, PT may also facilitate beneficial adaptations in the sensorimotor system that enhances dynamic restraint mechanisms (Swanik et al., 2002). PT is related with performance of stretch shortening cycle (SSC) movements that involve a highintensity eccentric contraction immediately after a rapid and powerful concentric contraction (Malisoux, Francaux, Nielens \& Theisen, 2006). SSC increases the capacity of the neural and muscle-tendon systems to produce maximum force in the shortest possible time, prompting the use of plyometric exercises as a bridge between strength and speed (Hortobagyi, Sio, Fodor \& Merkely, 1991). These exercises have been used to improve neuromuscular function, explosive performance and strength in athletic events (Markovic, Jukic, Milanovic, \& Metikos, 2007; Spurrs, Murphy, \& Watsford, 2003). It is important for gymnasts to have sufficient explosive strength in the musculature of the lower limbs to carry out the multitude of skills required for jumping while maintaining bodily control (Marina \& Jemni, 2014). Explosive strength, ground reaction time, flexibility and anthropometric features account for $41 \%$ of success in performing rhythmic gymnastics (Miletic, Katić \& Malès, 2004). PT for the lower limbs includes various types of bodyweight jumping-type exercises, such as drop jumps, countermovement jumps, alternate-leg bounding, hopping and other SSC jumping exercises (Fleck \& Kraemer, 2004). Women who take part in a PT programme present a significant reduction in the number of severe knee injuries (Hewett et al., 1996) as a result of neuromuscular adaptations which enhance dynamic knee stability and performance (Hewett, 2000). Other research has shown that PT improves performance in vertical jumping, as well as preventing injuries in adolescent gymnasts (Zelisko, Noble \& Porter, 1982).

The object of this study was to assess the efficiency of plyometric training in improving the performance of RG athletes in the juvenile and adult categories over 12 months, by incorporating PT into two training macrocycles.

\section{METHOD}

\section{Sample}

For this study 30 female athletes were selected intentionally in the juvenile and adult categories. They belonged to a Brazilian team which competes in regional and international tournaments. All the athletes in the adult categories and the parents or guardians of those in the juvenile categories signed an informed consent. This study was carried out in compliance with Brazilian bio-ethical regulatory criteria, the Helsinki Declaration and resolution 196/1996 of the Health Council. The anonymity and impersonality of the information were guaranteed. This study was approved by the Scientific Ethics Committee, protocol n ${ }^{\circ}$. 159516.

The athletes were divided randomly into a control group (CG) of 15 athletes (Mean age \pm SD: $15.2 \pm 1.5$ years; stature: $1.65 \pm 0.07 \mathrm{~m}$; years of experience: $7.5 \pm 1.6$; daily training time: $4 \pm 0.20$ hours); and an experimental group (EG) of 15 athletes (Mean age \pm SD: $15.4 \pm 1.2$ years; stature: $1.69 \pm 0.2 \mathrm{~m}$; years of experience: $7.5 \pm 1.8$; daily training time: $4 \pm 0.20$ hours).

\section{Instruments}

To analyse the performance of the CG and EG, three tests were carried out (vertical jump, horizontal jump and agility) at 5 moments during training: (1) pre-training; (2) 3 months after start of training; (3) at the end of the preparatory macrocycle; (4) 9 months after start of training; (5) at the end of the competitive macrocycle.

Test 1 - Vertical Jump (Cokolova \& Gaidukov, 2011): The object of this test was to measure the power of the lower limbs. An Abalakov belt (ABK) was used, in which a tape measure is attached to a belt worn round the athlete's waist. The tape measure slides through a guide on the floor between the athlete's feet, allowing the height of the jump to be measured. The athletes jumped, swinging their arms above their heads, and the height reached by the centre of gravity in the jump was 
measured. Each athlete made three jumps and only the highest result was recorded.

Test 2 - Horizontal Jump (Genadevna \& Karpenko, 2014): The athletes stood with their feet parallel and slightly apart, the toes behind a line. They swung their arms, as often as wished, as a preparatory movement to gain momentum but without flexing the knees. They jumped by swinging the arms forward, extending the hips, knees and ankles (helped by the preparatory movement), and the object was to jump as far forward as possible. Each athlete made three attempts and only the best result was recorded.

Test 3 - Agility (Golomazov \& Shirva, 1996): The "square agility test" was used, in which four cones are placed to form a 5 metre square. On the signal to start, the athlete runs forward from the first cone to the second, then sideways to the right from the second to the third, backwards to the fourth and sideways to the left to the starting point. The test is done clockwise. The athletes made two attempts and only the better time was recorded. The athlete must face forwards throughout the test. To run forward subject uses the acceleration of the posterior chain of the legs; to move sideways to the right subject uses the muscular capacity of the adductors and abductors; backwards, the contraction of the anterior leg muscles; and to the left the contralateral adductors and abductors. In this way the test assesses the various muscle groups of the legs and their integration in changes of direction during movement.

Table1

Preparatory macrocycle for rhythmic gymnastics with the addition of plyometric exercises, showing the intensity (\%) demanded in the microcycles

\begin{tabular}{|c|c|c|c|c|c|c|c|c|c|}
\hline \multirow{2}{*}{ Mesocycle } & \multirow{2}{*}{ Month } & \multirow{2}{*}{$\begin{array}{c}\text { Hours/ } \\
\text { day }\end{array}$} & \multirow{2}{*}{$\begin{array}{l}\text { Microcycle } \\
\text { Sequence }\end{array}$} & \multicolumn{6}{|c|}{ Microcycle Intensity } \\
\hline & & & & $\mathrm{R}$ & $\mathrm{I}$ & $\mathrm{O}$ & $S$ & $\mathrm{PC}$ & $\mathrm{C}$ \\
\hline Incorporation & 1 & 3 & $\mathrm{I}, \mathrm{O}$ & & $50 \%$ & $70 \%$ & & & \\
\hline Basic & 2 & 4 & $\mathrm{O}$ & & & $70 \%$ & & & \\
\hline Stabilisation & 3 & 5 & $\mathrm{O}, \mathrm{S}, \mathrm{O}, \mathrm{R}$ & $50 \%$ & & $70 \%$ & $100 \%$ & & \\
\hline Stabilisation & 4 & 4 & $\mathrm{O}, \mathrm{PC}, \mathrm{C}, \mathrm{R}$ & $50 \%$ & & $70 \%$ & & $80 \%$ & $100 \%$ \\
\hline Stabilisation & 5 & 4 & $\mathrm{O}, \mathrm{O}, \mathrm{S}, \mathrm{R}$ & $50 \%$ & & $70 \%, 80 \%$ & $100 \%$ & & \\
\hline Control and Recovery & 6 & 3 & $\mathrm{PC}, \mathrm{C}, \mathrm{O}, \mathrm{R}$ & $50 \%$ & & $80 \%$ & & $80 \%$ & $100 \%$ \\
\hline
\end{tabular}

I: Incorporation, O: Ordinary, S: Shock, R: Recovery, PC: Pre-competitive, C: Competitive

Table 2

Competitive macrocycle for rhythmic gymnastics with the addition of plyometric exercises, showing the intensity (\%) demanded in the microcycles

\begin{tabular}{|c|c|c|c|c|c|c|c|c|}
\hline \multirow{2}{*}{ Mesocycle } & \multirow{2}{*}{ Month } & \multirow{2}{*}{$\begin{array}{c}\text { Hours/ } \\
\text { day }\end{array}$} & \multirow{2}{*}{$\begin{array}{l}\text { Microcycle } \\
\text { Sequence }\end{array}$} & \multicolumn{5}{|c|}{ Microcycle Intensity } \\
\hline & & & & $\mathrm{R}$ & $\mathrm{O}$ & $S$ & PC & $\mathrm{C}$ \\
\hline \multirow{4}{*}{ Basic } & \multirow{4}{*}{7} & \multirow{4}{*}{3} & $\mathrm{O}$ & & $60 \%$ & & & \\
\hline & & & $\mathrm{O}$ & & $70 \%$ & & & \\
\hline & & & $\mathrm{O}$ & & $80 \%$ & & & \\
\hline & & & $\mathrm{O}$ & & $70 \%$ & & & \\
\hline Stabilisation & 8 & 4 & $\mathrm{O}, \mathrm{PC}, \mathrm{S}^{1}, \mathrm{R}$ & $50 \%$ & $70 \%$ & $100 \%$ & $80 \%$ & \\
\hline Stabilisation & 9 & 4 & $\mathrm{PC}, \mathrm{S}^{1}, \mathrm{R}, \mathrm{O}$ & $50 \%$ & $70 \%$ & $100 \%$ & $80 \%$ & \\
\hline Control & 10 & 4 & $\mathrm{O}, \mathrm{PC}, \mathrm{C}^{1}, \mathrm{R}$ & $50 \%$ & $70 \%$ & & $80 \%$ & $80 \%$ \\
\hline Pre-Competitive & 11 & 3 & $\mathrm{PC}, \mathrm{PC}, \mathrm{C}^{1}, \mathrm{R}$ & $50 \%$ & & & $80 \%, 90 \%$ & $100 \%$ \\
\hline Mixed & 12 & 3 & $\mathrm{PC}, \mathrm{PC}, \mathrm{C}^{1}, \mathrm{R}$ & $50 \%$ & & & $70 \%, 80 \%$ & $100 \%$ \\
\hline
\end{tabular}

${ }^{1}$ Competition, O: Ordinary, S: Shock, R: Recovery, PC: Pre-competitive, C: Competitive

\section{Procedures}

The CG maintained its training routine consisting of: stretching, joint warm-up, general warm-up, neuromotor warm-up (with and without apparatus), physical training, technical training (skills, dynamic rotation elements and running through routines) and wind-down. The EG athletes did PT in addition to normal training. Two 6-month macrocycles (preparatory and 
competitive) were drawn up using the principles of periodization (Tables 1 and 2).

The entire sequence followed the 4 methodological steps of PT described by Verkoshanski (1996) and adapted by contemporary authors (Damian, Popescu, Oltean, Traicu, \& Giurgiu, 2014). The plyometric exercises used in physical training were: two-leg jumps; alternate-leg bounding; step jumps and drop jumps from a box. PT was carried out after 10 minutes of moderate stretching using specific RG exercises; each PT session lasted on average 15 to 20 minutes. Strength training took place in blocks. After PT, technical training on apparatus (to improve movement precision) occurred normally. The model was divided into three logically grouped blocks: block A (special physical preparation) activates the mechanisms of the adaptation process and is oriented to the morphological and functional specialization of the organism; block B (technical-tactical preparation) assimilates the capacity to use the evolution of the loco-motor potential through a gradual increase in the intensity of execution of the competitive exercise; block C (competitions) ensures completion of the adaptation cycle and the body's ability to maximize the work done through competitions. Some of the contents of the blocks overlap so that the effects of the succeeding block benefit from delayed effects of training.

This periodization model was based on contemporary authors (Gomes, 2009; Platonov, 2014; Zatsiorski, 2004). As described above, PT was performed twice a week for 20 minutes in each basic mesocycle and in the first two weeks of the incorporation mesocycle. In the following two weeks there was an interval in PT, but the other components of training were maintained. PT was resumed 3 times per week in the control and mixed mesocycles. This plan followed the methodology proposed by Yuri Verkhoshanski, the creator of the method, who in the preparatory period recommended a 6 -week program with a frequency of 2 times per week, giving a total of 12 training sessions; or a variant of 5 weeks, with 3 weekly sessions, giving a total of 15 sessions. The author also states that the positive functional effect of concentrated force loads is not revealed immediately, but only after loading. After intensive small volume loading, it is possible to exceed these levels by 20 to $30 \%$ (Verkoshanski, 1996).

In the competitive macrocycle PT occurred during the whole basic mesocycle and in the first week of the stabilisation mesocycle 3 times per week for 20 minutes. There was a break for the three following weeks, and PT was re-started in the second stabilisation mesocycle twice a week for 20 minutes, and maintained at that level until the first week of the control mesocycle. Finally, at the start of the pre-competitive mesocycle the frequency was set at twice a week for 15 minutes until the second week of the mixed mesocycle. PT was interrupted in the penultimate week of the annual periodization, since this is a competitive microcycle when the last and most important competition of the cycle for this group of athletes occurs; only technical training continued (running through routines and correction of the most serious errors). During the last week of the mesocycle, in the recovery microcycle, PT was carried out twice in the week for 15 minutes.

The intensity of the exercises was controlled in direct relation to the training volume. In the shock and competitive microcycles, the intensity was $100 \%$. The indices achieved in these phases served as a parameter for controlling the intensity in the other microcycles.

\section{Statistical analysis}

Descriptive statistical and normality tests were done using SAS System 9.0. ANOVA with repeated measurements was used for data with normal distribution, followed by Tukey's multiple comparison test whenever a statistically significant effect was identified in the factor. Three models of ANOVA were developed, always with the particular measurements (vertical jump, horizontal jump and agility) as dependent variables and the factors (group, time with repeated measurements, and group-time interaction) as independent variables. The magnitude of the effect was analysed by Cohen's $d$ and classified as very small (0.01), small (0.29), medium (0.50), large (0.80), very large (1.20) and enormous (2.00), according to Sawilowsky (2009). 
The significance level used in testing the hypotheses developed in this work was $5 \%$.

\section{RESULTS}

The p-value, standard deviation, effect size and mean values found for the vertical jump, horizontal jump and agility tests are described in Tables 3, 4 and 5 respectively.

\section{Test 1 - Vertical Jump}

Both groups presented an increase in the height achieved in the vertical jump from the pretraining period to the end of the 12 months ( $\mathrm{p}<$ 0.0001). We observed that the mean height recorded for the CG increased from $34.27 \mathrm{~cm}$ to $44.0 \mathrm{~cm}$, an increase of $28.40 \%$, while that of the EG increased from $35.80 \mathrm{~cm}$ to $50.93 \mathrm{~cm}$, an increase of $42.26 \%$. The EG therefore presented a greater improvement than the CG with a statistically significant difference between groups $(\mathrm{p}=0.009)$. A statistically significant difference was observed in the increased height of the vertical jump after 6 months $(\mathrm{p}=0.0008), 9$ months $(\mathrm{p}<.0001)$ and 12 months $(\mathrm{p}<.0001)$ of training for both the CG and the EG. The magnitude of the effect after 6,9 and 12 months was medium, large and very large respectively.

Table 3

Mean values, standard deviation (SD) and p-value found for the vertical jump test for the control (CG) and experimental (EG) groups

\begin{tabular}{|c|c|c|c|c|c|c|c|}
\hline \multirow{3}{*}{ Test } & \multirow{3}{*}{ Period of time } & \multicolumn{3}{|c|}{ Groups } & \multirow{3}{*}{ Cohen's $d$} & \multirow{3}{*}{$\begin{array}{c}\text { P-value } \\
\text { between } \\
\text { groups }\end{array}$} & \multirow{3}{*}{$\begin{array}{l}\text { P-value time } \\
(\mathrm{EG}+\mathrm{CG})\end{array}$} \\
\hline & & \multicolumn{2}{|c|}{ CG $(n=15)$} & EG $(n=15)$ & & & \\
\hline & & Mean & SD & Mean SD & & & \\
\hline \multirow{5}{*}{ Vertical jump $(\mathrm{cm})$} & Pre-training & 34.27 & \pm 6.08 & $35.80 \pm 6.97$ & 0.242 & \multirow{5}{*}{$0.009 *$} & \multirow{5}{*}{$<.0001$} \\
\hline & 3 months & 37.60 & \pm 6.25 & $38.80 \pm 7.07$ & 0.186 & & \\
\hline & 6 months & 40.47 & \pm 7.03 & $41.53 \pm 6.72$ & 0.160 & & \\
\hline & 9 months & 42.33 & \pm 7.21 & $46.07 \pm 6.79$ & 0.553 & & \\
\hline & 12 months & 44.00 & \pm 7.64 & $50.93 \pm 47.47$ & 1.078 & & \\
\hline
\end{tabular}

\section{Test 2 - Horizontal Jump}

We observed that the distance of the horizontal jump in the CG increased from $1.70 \mathrm{~m}$ to $1.93 \mathrm{~m}$, an increase of $13.52 \%$, while in the EG it increased from $1.69 \mathrm{~m}$ to $2.05 \mathrm{~m}$, an increase of $21.30 \%$. The EG therefore presented a greater improvement than the CG with a statistically significant difference between groups $(\mathrm{p}=$ 0.001).

Table 4

Mean values, standard deviation (SD) and p-value found for the horizontal jump test for the control (CG) and experimental (EG) groups

\begin{tabular}{|c|c|c|c|c|c|c|c|c|}
\hline \multirow{3}{*}{ Test } & \multirow{3}{*}{ Period of time } & \multicolumn{4}{|c|}{ Groups } & \multirow{3}{*}{ Cohen's $d$} & \multirow{3}{*}{$\begin{array}{c}\text { P-value } \\
\text { between } \\
\text { groups }\end{array}$} & \multirow{3}{*}{$\begin{array}{l}\text { P-value } \\
\text { time } \\
(\mathrm{EG}+\mathrm{CG})\end{array}$} \\
\hline & & \multicolumn{2}{|c|}{ CG $(n=15)$} & \multicolumn{2}{|c|}{ EG $(n=15)$} & & & \\
\hline & & Mean & $\mathrm{SD}$ & Mean & $\mathrm{SD}$ & & & \\
\hline \multirow{5}{*}{$\begin{array}{l}\text { Horizontal } \\
\text { jump } \\
\text { (m) }\end{array}$} & Pre-training & 1.70 & \pm 0.06 & 1.69 & \pm 0.09 & 0.135 & \multirow{5}{*}{$0.001^{*}$} & \multirow{5}{*}{$<.0001^{*}$} \\
\hline & 3 months & 1.76 & \pm 0.07 & 1.77 & \pm 0.10 & 0.120 & & \\
\hline & 6 months & 1.82 & \pm 0.06 & 1.85 & \pm 0.11 & 0.350 & & \\
\hline & 9 months & 1.87 & \pm 0.06 & 1.96 & \pm 0.12 & 0.982 & & \\
\hline & 12 months & 1.93 & \pm 0.07 & 2.05 & \pm 0.12 & 1.264 & & \\
\hline
\end{tabular}

The CG presented an increase in distance in the horizontal jump after 3 months $(p=0.03), 6$ months ( $\mathrm{p}<0.0001), 9$ months $(\mathrm{p}<0.0001)$ and 12 months $(p<0.0001)$ of training. The EG presented an increase in distance in the horizontal jump after 3 months $(p=0.01), 6$ months ( $\mathrm{p}<0.0001), 9$ months $(\mathrm{p}<0.0001)$ and 12 months $(p<0.0001)$ of training with the addition of plyometric exercises. The magnitude of the effect after 9 and 12 months was large and very large respectively. 


\section{Test 3 - Agility test}

After one year of training, the CG presented a reduction in the time taken to do the agility test from 7.29 to 6.96 seconds, a reduction of $4.74 \%$; the EG presented better agility performance after plyometric training, with test time reduced from 7.32 to 6.58 seconds, an improvement of $11.24 \%$. The EG therefore presented a greater improvement than the CG with a statistically

Table 5

Mean values, standard deviation (SD) and p-value found for the agility test for the control (CG) and experimental (EG) groups

\begin{tabular}{|c|c|c|c|c|c|c|c|c|}
\hline \multirow{3}{*}{ Test } & \multirow{3}{*}{ Period of time } & \multicolumn{4}{|c|}{ Groups } & \multirow{3}{*}{ Cohen's $d$} & \multirow{3}{*}{$\begin{array}{c}\text { P-value } \\
\text { between } \\
\text { groups }\end{array}$} & \multirow{3}{*}{$\begin{array}{c}\text { P-value time } \\
(\mathrm{EG}+\mathrm{CG})\end{array}$} \\
\hline & & \multicolumn{2}{|c|}{ CG $(n=15)$} & \multicolumn{2}{|c|}{$\mathrm{EG}(n=15)$} & & & \\
\hline & & Mean & SD & Mean & SD & & & \\
\hline \multirow{5}{*}{ Agility (s) } & Pre-training & 7.29 & \pm 0.34 & 7.32 & \pm 0.36 & 0.089 & \multirow{5}{*}{$0.004^{*}$} & \multirow{5}{*}{$<.0001^{*}$} \\
\hline & 3 months & 7.24 & \pm 0.34 & 7.24 & \pm 0.33 & 0.000 & & \\
\hline & 6 months & 7.17 & \pm 0.35 & 7.04 & \pm 0.31 & 0.407 & & \\
\hline & 9 months & 7.10 & \pm 0.35 & 6.84 & \pm 0.27 & 0.861 & & \\
\hline & 12 months & 6.96 & \pm 0.32 & 6.58 & \pm 0.27 & 1.329 & & \\
\hline
\end{tabular}

*statistically significant

\section{DISCUSSION}

The incorporation of plyometric exercises in athletes' training reduces the risk of injury by improving the functional stability of leg joints (Chimera et al., 2004). It should be noted however that initial training with PT must be at low to moderate intensity and concentrate on technical proficiency in the exercises to avoid injury (Bishop, Smith, Smith \& Rigby, 2009). Furthermore, the exercises must be specific to the movements in which the increased energy production is required, and the overload should be built up gradually by increasing the intensity and volume of training (Marina \& Jemni, 2014). It should further be noted that the gymnasts produced greater mechanical power during repetitive maximal jumping exercises, but also get tired rapidly (Kums, Ereline, Gapeyeva \& Pääsuke, 2005).

The results of the present study were significant in quantitative and qualitative parameters for the performance of RG athletes. PT also improves arm-leg coordination (Ridderikhoff, Batelaan, \& Bobbert, 1999; Vittori, 1990), which may explain the improved performance of athletes trained with the addition of this method. The literature shows that PT improves scores in jumping ability by $57 \%$, and that $43 \%$ of this is due to gains in muscle strength significant difference between groups $(\mathrm{p}=$ 0.004)

We also observed that both groups presented a progressive reduction in test times, with a statistically significant difference observed between the time at the start of training and the times recorded after 6 months $(p=0.01), 9$ months $(p<0.001)$ and 12 months $(p<0.001)$. The magnitude of the effect after 9 and 12 months was large and very large respectively.
(Bosco, Vittori \& Matteuci, 1995; Brown, Mayhew \& Boleach, 1986; Church, Wiggins, Moode, \& Crist, 2001). Vertical jumps can be used as a model to assess the explosive strengthgenerating capacity and anaerobic power of the leg extensor muscles (Bosco et al., 1982). In a study of 20 female athletes (10 EG, 10 CG), aged 17 to 20 years, with $11 \pm 14$ years' experience, (Taktak, TakTak, \& Shephard, 2014) found increases of 6 and $7 \mathrm{~cm}$ in the height of squat jumps and counter-movement jumps, respectively, in the experimental group after 12 weeks of PT, while in the control group, an increase of $1 \mathrm{~cm}$ was observed in squat jumps and no change in counter-movement jumps. These authors also report that PT showed a significant increase in the athletes' explosive strength, a finding that coincides with the results of the present study.

The finding of increased jump heights in the results obtained in competitions during the competitive macrocycle showed that PT is an important tool for use in long-term planning in this sport. The specific effects of PT on jump height in different types of vertical jumps could be of particular importance. It has been suggested that PT is more effective in improving vertical jump performance in SSC jumps as it enhances the ability of subjects to use the elastic and neural 
benefits of SSC (Wilson, Newton, Murphy \& Humphries, 1993). After 12 months, the athletes in our study who trained with plyometric exercises obtained an improvement of $42.26 \%$ in the vertical jump test. Other studies also reported excellent improvements with PT, ranging from $18.2 \%$ to $31.8 \%$ (Diallo, Dore, Duche \& Van Praagh, 2001; Kyröläinen et al., 2005; Spurrs et al., 2003).

In our study both groups presented an increase in horizontal jump after 9 and 12 months of training; however, the group subjected to PT presented better test results than the CG. In the literature an improvement of 1.4 to $7.0 \%$ is reported in the horizontal jump with use of PT (Grosset, Piscione, Lambertz, \& Pérot, 2009; Hortobagyi, Havasi \& Varga, 1990; Hortobagyi et al., 1991; Markovic et al., 2007; Spurrs et al., 2003; Paavolainen, Häkkinen, Hämäläinen, Nummela, \& Rusko, 1999). These values are lower than those found in the present study for the group trained with plyometric exercises after a period of 12 months (EG: $21.30 \%$ ).

Agility has been defined as a rapid whole-body movement with change of velocity or direction in response to a stimulus (Sheppard \& Young, 2006). Most of agility tasks demand a rapid change from eccentric to concentric muscle action in the leg extensor muscles (SSC muscle function). Plyometric exercises can diminish ground reaction times in tests by increasing the production of muscular strength and movement efficiency, with a positive effect on agility performance (Roper, 1998). In our study both the CG and the EG presented better performance in the agility test after 12 months of training, but the improvement was greater in the group subjected to PT. Other studies have reported increased agility after PT with improvements of 1.5 to $10.2 \%$ (Malisoux et al., 2006; Markovic et al., 2007; Miller, Herniman, Ricard, Cheatham, \& Michael, 2006; Salonikidis, \& Zafeiridis, 2008) and in our study, after 12 months, the group trained with plyometric exercises improved its performance in the agility test by $11.24 \%$.

In a randomized, controlled study, Piazza et al. (2014) determined the effectiveness of two strength training programs on lower limb explosive and reactive strength in young female athletes using the squat jump test, counter movement jump test and hopping test after six weeks of training. These authors reported that the two protocols had a positive effect on jumping performance, with an increase of $6-7 \%$ in lower limb explosive strength. However, they stated that, owing to the fact that the athletes continued their normal sports activity during the intervention period, it was difficult to determine the independent contribution of each strength protocol to the improvement in muscular power. Other authors stress the need to clarify whether improvement in performance of the athletes who train with plyometric exercises is due to the quality of the PT or to the increase in the number of hours that the athletes devoted to training (Hall, Bishop \& Gee, 2016). In our study the athletes who trained with normal exercises (CG) and the athletes who trained with the addition of plyometric exercises (EG) were subjected to the same number of hours of training/day/week, suggesting that the improvement in the EG athletes was due to PT.

According to Douda, Toubekis, Avloniti and Tokmakidis (2008), selected anthropometric characteristics (body mass, arm span, circumferences and diameters), aerobic power, flexibility and explosive strength are important determinants of successful performance by RG athletes. The literature says that PT is effective for increasing flexibility (Gaiole \& Patil, 2016) and improving explosive power (Mirela et al., 2014) in athletes. It also contributes to weight control (Piazza et al., 2014), helping them to maintain a slender, "light" body, which is a requisite for RG (Di Cagno et al., 2010). In our research we also found greater agility and increased distances in vertical and horizontal jumps. In a study to assess the effectiveness of a combined strength and plyometric training program (experimental period) on jumping performance when compared with a training routine on apparatus (control period), Marina and Jemni (2014) analysed the jump performance of 9 female elite-orientated gymnasts. The authors concluded that a combination of heavy strength training with high impact plyometric jumps is effective in pre-pubertal gymnasts. In another study, Hall et al. (2016) evaluated the 
effect of a PT intervention added to habitual gymnastic training on handspring vault performance and lower body power development in a group of 20 athletes (10 EG, 10 CG), mean age of 12.5 years, with at least three years of experience, where the EG were subjected to $10 \mathrm{~h}$ per week of PT during 6 weeks. It was found that after PT the athletes presented a small but significant increase in post-flight time.

As both groups, control and experimental, carried out the same hours of training, and the experimental group obtained better performance, we agree with Marina and Jemni (2014) that time devoted to physical condition training designed to optimize the plyometric skills of gymnasts should be increased at the expense of time spent on technical routines.

There are few studies reported in the literature which analysed the effects of PT on RG athletes; moreover, other tests are used to quantify the effectiveness of the PT intervention, making it difficult to compare the findings reported in the literature with the findings of our study. One limitation of our study was the sample size. A future study could be done with a larger sample to make it more representative, with a larger number of data, as this would reduce the risk of bias in the investigation.

\section{CONCLUSIONS}

In our study all the athletes presented improvements in performance after the 12 months of the training period, however the athletes trained with the addition of plyometric exercises presented better performance than the group trained with normal exercises, with greater strength in the lower limbs in vertical jump and horizontal jump, and improved agility.

\section{Acknowledgments:}

Nothing to declare

\section{Conflict of interest:}

Nothing to declare

Funding:

Nothing to declare

\section{REFERENCES}

Adams, K., O'shea, J. P., O'shea, K. L., \& Climstein, M. (1992). The effect of six weeks of squat, plyometrics and squat-plyometric training on power production. Journal of Applied Sport Science Research, 6(1), 36-41.

Bishop, D. C., Smith, R. J., Smith, M. F., \& Rigby, H. E. (2009). Effect of Plyometric Training on Swimming Block Start Performance in Adolescents. Journal of Strength and Conditioning Research, 23(7), 2137-2143. doi: 10.1519/JSC.0b013e3181b866d0

Bosco, C., Ito, A., Komi, P. V., Luhtanen, P., Rahkila, P., Rusko, H., \& Viitasalo, J. T. (1982). Neuromuscular function and mechanical efficiency of human leg extensor muscles during jumping exercises. Acta Physiologica Scandinavica, 114(4), 543-550.

Bosco, C., Vittori, C., \& Matteuci, E. (1995). Considerazioni sulle variazzioni dinamiche di alcuni parametric biomeccanici nela corsa. Atleticastudi, 2, 155-162.

Brown, M. E., Mayhew, J. L., \& Boleach, L. W. (1986). Effect of plyometric training on vertical jump performance in high school basketball players. Journal of Sports Medicine and Physical Fitness, 26(1), $1-4$

Chimera, N. J., Swanik, K. A., Swanik, C. B., \& Straub S. J. (2004). Effects of plyometric training on muscle-activation strategies and performance in female athletes. Journal of Athletic Training, 39(1), 24-31.

Church, J. B.; Wiggins, M. S., Moode, F. M., \& Crist, R. (2001). Effect of warm-up and flexibility treatments on vertical jump performance. Journal of Strength \& Conditioning Research, 15(3), 332-336.

Cokolova, N. M., \& Gaidukov, E. A. (2011). Sport selection and prognosis of the results of track and field athletes aged 10-12 years old based on the analysis of motor readiness. Scientific journal of the University of Lesgaft, 4(74), 796-799.

Damian, M., Popescu, R., Oltean, A., Traicu, C., \& Giurgiu, L. (2014). Plyometric exercises to improve explosive power in artistic gymnastics. Science, Movement and Health, 14(2), 381-386.

Diallo, O., Dore, E., Duche, P., \& Van Praagh, E. (2001). Effects of plyometric training followed by a reduced training program on physical performance in prepubescent soccer players. The Journal of Sports Medicine and Physical Fitness, 41 (3), 342-348.

Di Cagno, A., Baldari, C., Battaglia, C., Gallotta, M. C., Videira, M., Piazza, M., \& Guidetti, L. (2010). Preexercise static stretching effect on leaping performance in elite rhythmic gymnasts. Journal of Strength and Conditioning Research, 24(8), 19952000.

Douda, H. T., Toubekis, A. G., Avloniti, A. A., \& Tokmakidis, S. P. (2008). Physiological and anthropometric determinants of rhythmic gymnastics performance. International Journal of 
Sports Physiology and Performance, 3, 41-54.

Fleck, S. J., \& Kraemer, W. J. (2004). Designing resistance training program. Champaign: Human Kinetics.

Gaiole, R., \& Patil, P. P. (2016). Plyometric training effect on flexibility in female puberal gymnasts. International Journal of Therapies and Rehabilitation Research, 5, 1.

Genadevna, R. O., \& Karpenko, L. A. (2014). Teoria e metodologia da preparação física na ginástica rítmica estética. Moscou.

Golomazov, S., \& Shirva, B. (1996). Futebol: treino da qualidade do movimento para atletas jovens. São Paulo: Livraria Aratebi.

Gomes, A. C. (2009). Treinamento desportivo: estruturação e periodização. Porto: Artmed.

Grosset, J. F., Piscione, J., Lambertz, D., \& Pérot, C. (2009). Paired changes in electromechanical delay and musculo-tendinous stiffness after endurance or plyometric training. European Journal of Applied Physiology, 105(1), 131-139. doi: 10.1007/s00421-008-0882-8.

Hewett, T. E. (2000). Neuromuscular and hormonal factors associated with knee injuries in female athletes: strategies for intervention. Sports Medicine, 29, 313-327.

Hewett, T. E., Stroupe, A. L., Nance, T. A., \& Noyes, F. R. (1996). Plyometric training in female athletes: decreased impact forces and increased hamstring torques. American Journal of Sports Medicine, 24(6), 765-773.

Hall, E., Bishop, D. C., \& Gee, T. I. (2016). Effect of plyometric training on handspring vault performance and functional power in youth female gymnasts. Public Library of Science One, 11(2), e0148790. doi: 10.1371/journal.pone.0148790

Hortobagyi, T., Havasi, J., \& Varga, Z. (1990). Comparison of two stretch-shorten exercise programs in 13-year-old-boys: nonspecific training effects. Journal of Human Movements Studies, 18(4), 177-188.

Hortobagyi, T., Sio, A., Fodor, T., \& Merkely, B. (1991). Effects of targeted skill development and plyometric conditioning on long jump performance in 16-year-old boys. Journal of Human Movements Studies, 21 (1), 1-17.

Kums, T., Ereline, J., Gapeyeva, H., \& Pääsuke, M. (2005). Vertical jumping performance in young rhythmic gymnasts. Biology of Sport, 22(3), 237246.

Kyröläinen, H., Avela, J., McBride, J. M., Koskinen, S., Andersen, J. L., Sipilä S, Takala, T. E., \& Komi, P. V. (2005). Effects of power training on muscle structure and neuromuscular performance. Scandinavian Journal of Medicine $\mathcal{E}$ Science in Sports, 15(1), 58-64.

Maffuli, N. (1990). Intensive training in young athletes: An orthopaedic surgeons view point. Sports Medicine, 9(4), 229-243.

Malisoux, L., Francaux, M., Nielens, H., \& Theisen, D. (2006). Stretch-shortening cycle exercises: an effective training paradigm to enhance power output of human single muscle fibers. Journal of Applied Physiology, 100(3), 771-779. doi: 10.1152/japplphysiol.01027.2005

Marina, M., \& Jemni, M. (2014). Plyometric training performance in elite-oriented pre-pubertal female gymnasts. Journal of Strength and Conditioning Research, 28(4), 1015-1025.

Markovic, G., Jukic, I., Milanovic, D., \& Metikos, D. (2007). Effects of sprint and plyometric training on muscle function and athletic performance. Journal of Strength and Conditioning Research, 21 (2), 543-549.

Miletic, D., Katić, R., \& Malès, B. (2004). Some anthropologic factors of performance in rhythmic gymnastics novices. Collegium Antropologicum, 28(2), 727-737.

Miller, M. G., Herniman, J. J., Ricard, M. D., Cheatham, C. C., \& Michael, T. J. (2006). The effects of a 6week plyometric training program on agility. Journal of Sports Science \& Medicine, 5(3), 459-465.

Mirela, D., Raducu, P., Antoanela, O., Carmen, T., \& Laura G. (2014). Plyometric exercises to improve explosive power in artistic gymnastics. Science, Movement and Health, 14(2, Supplement), 281286.

Paavolainen, L., Häkkinen, K., Hämäläinen, I, Nummela, A., \& Rusko, H. (1999). Explosivestrength training improves $5-\mathrm{km}$ running time by improving running economy and muscle power. Journal of Applied Physiology, 86(5), 1527-1533.

Piazza, M., Battaglia, C., Fiorilli, G., Innocenti, G., Iuliano, E., Aquino, G., Calcagno, G., Giombini, A., \& Di Cagno, A. (2014). Effects of resistance training of jumping performance in preadolescent rhythmic gymnasts. A randomized controlled study. Italian Journal of Anatomy and Embriology, 119(1), 10-19.

Platonov, V. N. (2014). Sistema de preparação de atletas nos esportes olímpicos. Kiev: Literatura Olímpica.

Ridderikhoff, A., Batelaan, J. H., \& Bobbert, M. F. (1999). Jumping for distance: control of the external force in squat jumps. Medicine and Science in Sports and Exercise, 31 (8), 1196-1204.

Roper, R. L. (1998). Incorporating agility training and backward movement into a plyometric program. Strength and Conditioning Journal, 20(4), 60-63.

Salonikidis, K., \& Zafeiridis, A. (2008). The effects of plyometric, tennis-drills, and combined training on reaction, lateral and linear speed, power, and strength in novice tennis players. Journal of Strength and Conditioning Research, 22(1), 182-191.

Sawilowsky, S. S. (2009). New effect size rules of thumb. Journal of Modern Applied Statistical Methods, 8(2), 597-599.

Sheppard, J. M., \& Young, W. B. (2006). Agility literature review: classification, training and testing. Journal of Sports Sciences, 24(9), 919-932.

Spurrs, R. W., Murphy, A. J., \& Watsford, M. L. (2003). The effect of plyometric training on distance running performance. European Journal of Applied Physiology, 89(1), 1-7. 
Swanik, K. A., Lephart, S. M., Swanik, C. B., Lephart, S. P., Stone, D. A., \& Fu, F. H. (2002). The effects of shoulder plyometric training on proprioception and selected muscle performance characteristics. Journal of Shoulder Elbow Surgery, 11, 579-586.

Taktak, F., TakTak, I., \& Shephard, R. J. (2013). A controlled trial of plyometric training for rhythmic female gymnasts. Health \& Fitness Journal of Canada, 6(3), 123-131.

Verkoshanski, Y. (1996). Força: treinamento da potência muscular. Londrina: CID.

Vittori, C. (1990). El entrenamiento de la fuerza para el sprint. Red: revista de entrenamiento deportivo, 4(3), 2-8.

Wilson, G. J., Newton, R. U., Murphy, A. J., \& Humphries, B. J. (1993). The optimal training load for the development of dynamic athletic performance. Medicine and Science in Sports $\mathcal{E}$ Exercise, 25(11), 1279-1286.

Wright, K. J., \& De Cree, C. (1998). The influence of somatotype, strength and flexibility on injury occurrence among female competitive Olympic style gymnasts - A pilot study. Journal of Physical Therapy Science, 10, 87-92.

Zatsiorsky, V. M. (2004). Biomecânica do desempenho e prevenção de lesão. Rio de Janeiro: Guanabara Koogan.

Zelisko, J. A., Noble, H. B., \& Porter, M. (1982). A comparison of men's and women's professional basketball injuries. The American Journal of Sports Medicine, 10(5), 297-299.

All content of Journal Motricidade is licensed under Creative Commons, except when otherwise specified and in content retrieved from other bibliographic sources. 